\title{
Osteonecrose mandibular associada ao uso de bisfosfonatos tratada com plasma rico em fibrina leucocitária: relato de caso
}

\section{Jaw osteonecrosis associated with the use of bisphosphonates treated with fibrin rich plasma leukocyte: case report}

\author{
Maria Gisela Buitrago Duque* \\ Ana Sofia Ribeiro** \\ João Batista Burzlaff ** \\ Vinicius Salim Silveira ${ }^{* * * *}$ \\ Leonardo Tonietto ${ }^{* * * *}$ \\ Thiago Calcagnotto ${ }^{* * * * *}$
}

\section{Resumo}

Bisfosfonatos são antiabsortivos que agem especificamente sobre a atividade dos osteoclastos. Uma complicação grave do seu uso é a osteonecrose dos maxilares, definida como uma área de exposição óssea na região maxilofacial sem resolução espontânea por um período de no mínimo oito semanas em pacientes com histórico de uso de compostos bisfosfonatos, mas que não foram submetidos à radioterapia na região de cabeça e pescoço. Tratamentos conservadores são recomendados, mas os resultados da literatura são controversos e nem sempre efetivos. Por isso, novas abordagens, como o uso dos concentrados plaquetários, têm sido sugeridas. São produtos autólogos que contém altas concentrações de fatores de crescimento e que atuam como moléculas de adesão celular, acelerando o reparo ósseo. Objetivo: descrever, por meio de relato de caso, o uso do plasma rico em fibrina e leucocitária (L-PRF) como forma de tratamento da osteonecrose mandibular. Relato do caso: paciente do gênero feminino, 79 anos, diagnosticada com osteonecrose mandibular associada ao uso de bisfosfonatos, tratada por meio de cirurgia convencional associando curetagem óssea e rotação de retalho, mas sem sucesso. Então, foi submetida à modificação de técnica cirúrgica, associando o uso de plasma rico em fibrina leucocitária (L-PRF), a fim de acelerar o processo de reparo ósseo e garantir a cicatrização dos tecidos moles. Considerações finais: o uso de L-PRF como tratamento da osteonecrose mandibular estimula o reparo ósseo e acelera a cicatrização dos tecidos moles, sendo uma alternativa eficaz de tratamento.

Palavras-chave: Bisfosfonatos. L-PRF. PRF. Osteonecrose.

\section{Introdução}

Os bisfosfonatos são fármacos antiabsortivos que atuam especificamente sobre a atividade dos osteoclastos. São utilizados em muitas situações clínicas, incluindo a prevenção e o tratamento de osteoporose primária e secundária, doença de Paget, hipercalcemia, mieloma múltiplo e osteólise associada a metástases ósseas de tumores malignos. Um dos principais eventos adversos graves é a osteonecrose dos maxilares associada ao uso dos compostos bisfosfonatos, que é definida como uma área de exposição óssea e necrose tecidual incapaz de cicatrizar em um período de oito semanas em um paciente com história de uso de bisfosfonatos e sem história de radioterapia local ${ }^{1}$.

Inicialmente, a fisiopatologia da osteonecrose mandibular foi definida como uma complicação da radioterapia da região de cabeça e pescoço. O nome osteonecrose é normalmente usado para designar morte óssea devido à falta de suprimento sanguíneo adequado no local. Assim, uma relação da ocorrência de osteonecrose associada ao uso de bisfosfonatos consiste no efeito isquêmico desses compostos sobre os vasos sanguíneos, afetados pela inibição de fator de crescimento endotelial vascular, que leva às lesões necróticas nos ossos. Mais recentemente, 
tem sido sugerido que a osteonecrose mandibular não começa como uma forma de osteonecrose clássica, mas a partir de uma osteomielite, caracterizada pela inflamação óssea com envolvimento cortical e medular, geralmente causada pela invasão bacteriana local $^{2}$. Contudo, a mucosa oral poderia desempenhar um papel significativo na osteonecrose mandibular: os bisfosfonatos que se acumulam no tecido ósseo têm efeitos tóxicos diretos no epitélio oral e inibem a cicatrização normal de lesões nesses tecidos, sejam lesões causadas por intervenção dentária ou algum outro trauma associado a uma supressão excessiva da remodelação ${ }^{3}$.

O histórico de uso de bisfosfonatos e a realização de procedimentos cirúrgicos que exponham tecido ósseo na cavidade oral, como as extrações dentárias e os implantes, são fatores que aumentam o risco de osteonecrose mandibular ${ }^{4}$. Outros pacientes, sem nenhum tratamento aparente, podem apresentar osteonecrose mandibular associada ao uso contínuo de bisfosfonatos, por períodos de 1,5 a 3 anos. Fatores de risco relacionados à osteonecrose mandibular incluem o tempo de uso do medicamento, o fármaco utilizado, a concentração e as vias de administração, além da exposição óssea cirúrgica na cavidade oral.

Novas alternativas de tratamento para osteonecrose da mandíbula associada ao uso de bisfosfonatos é o concentrado de plasma rico em fibrina leucocitária (L-PRF), material autólogo que tem como objetivo acelerar e favorecer a remodelação, a cura e a cicatrização dos tecidos moles e duros. Esses efeitos estimulantes estão relacionados à concentração de fatores de crescimento contidos nas plaquetas e que são liberados durante o processo de centrifugação para a obtenção das membranas de L-PRF5.

Assim, este trabalho tem o objetivo de descrever, por meio de relato de caso, o uso do plasma rico em fibrina leucocitária L-PRF como forma de tratamento em caso de osteonecrose associada ao uso de compostos bisfosfonatos.

\section{Relato de caso}

Uma paciente do sexo feminino, leucoderma, 79 anos, edêntula total, portadora de prótese total mucossuportada superior e prótese mucoimplantossuportada inferior do tipo overdenture, com sistema barra-clip, que relatou uso de doses orais diárias de $10 \mathrm{mg}$ de Alendronato de sódio, durante um período de 20 anos, para tratamento preventivo de osteoporose, procurou atendimento com queixa de dor relacionada à lesão hiperplásica localizada na crista do rebordo na região em que estariam os dentes 46 e 47 (Figura 1A). Na anamnese, a paciente referiu dor relacionada à presença da lesão ulcerada associada à exposição óssea ocorrida em setembro de 2016, confirmada com o exame tomográfico (Figura 1B), que evidenciou imagem de sequestro ósseo na região.

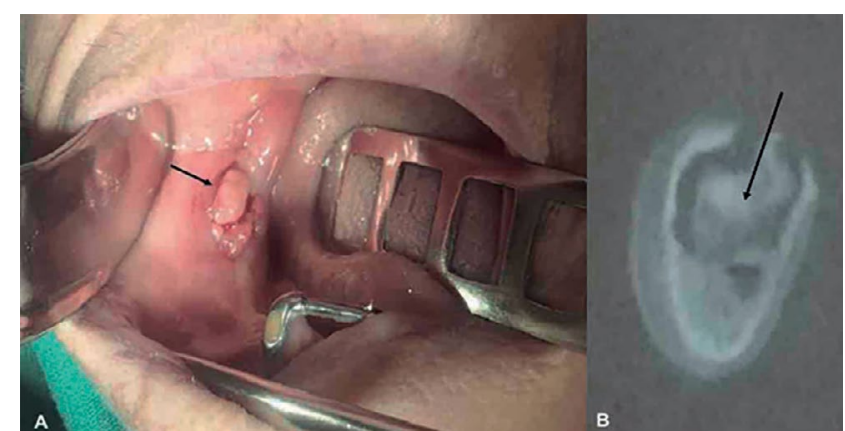

Figura 1 - A) Imagem clínica de lesão hiperplásica (indicada pela seta) localizada na crista do rebordo na região em que estariam os dentes 46 e 47, com cerca de $15 \mathrm{~mm}$ no seu maior diâmetro, coloração avermelhada nos bordos e aspecto ulcerado na porção central, com drenagem purulenta associada - B) Imagem tomográfica pré-operatória da osteonecrose mandibular e área de sequestro ósseo no interior (indicada pela seta)

Fonte: elaboração dos autores.

A paciente relatou que a lesão teve início aproximadamente três meses após instalação da prótese mucoimplantossuportada inferior, com histórico de intervenção cirúrgica prévia por meio de exérese da lesão ulcerada associada à curetagem óssea e rotação de retalho, porém, com deiscência de sutura por falha no processo cicatricial após oito dias. Ela relatou, ainda, desadaptação da prótese inferior associada à movimentação ínfero-superior da porção posterior da prótese, durante a mastigação, a fala e a movimentação da língua. Essa movimentação ínfero-superior da porção distal da prótese gerava dor devido ao trauma contínuo na região posterior do rebordo alveolar, local onde estariam os dentes 46 e 47.

$\mathrm{Na}$ avaliação sistêmica, a paciente referiu histórico médico de hipertensão arterial, osteoporose, ansiedade generalizada e labirintite, fazendo uso contínuo de Amlodipina 2,5 mg/dia, Ginkgo Biloba, vitamina D $400 \mathrm{UI} /$ dia, Citalopram $20 \mathrm{mg} /$ dia e Cloxazolam $2 \mathrm{mg} /$ dia, além do já relatado uso diário de Alendronato de sódio $10 \mathrm{mg}$ por via oral durante vinte anos, que foi suspenso por orientação do cirurgião bucomaxilofacial que realizou a primeira intervenção na paciente.

O exame clínico extrabucal não evidenciou anormalidades, já o quadro clínico intrabucal apresentou lesão hiperplásica e ulcerada (quando o tecido hiperplásico foi levantado e examinado com pinça odontológica) na região da crista do rebordo alveolar, onde estariam os dentes 46 e 47, conforme Figura 1A. Essa lesão apresentava-se com cerca de $15 \mathrm{~mm}$ no seu maior diâmetro, com coloração avermelhada nos bordos e aspecto ulcerado na porção central, com drenagem purulenta associada e, ainda, exposição de tecido ósseo na sua porção mais central.

O exame tomográfico de imagem evidenciou área hipodensa no rebordo alveolar da região posterior de mandíbula à direita (Figura 1B), contendo, no seu interior, uma imagem hiperdensa, com dimensões aproximadas de $10 \mathrm{~mm}$ x $12 \mathrm{~mm}$, compatível com área de sequestro ósseo. 
Devido à recidiva da lesão três semanas após a primeira intervenção cirúrgica, a paciente foi encaminhada pelo seu cirurgião para reintervenção em ambiente hospitalar, sob anestesia geral, com indicação de realização de remoção segmentar parcial por meio de acesso externo. O tratamento cirúrgico proposto, contudo, foi conservador, tendo indicação de ser realizado em regime ambulatorial, sob efeito de anestesia local com Cloridrato de Articaína 4\% (DFL Indústria e Comércio S.A., Rio de Janeiro, Brasil) e sem uso de sedação, mas em ambiente hospitalar, para viabilizar o uso de medicações endovenosas no pós-operatório imediato.

A anestesia local foi realizada por meio de bloqueio troncular dos nervos alveolar inferior e lingual. Em seguida, foi feita uma incisão linear sobre a crista do rebordo alveolar, estendendo-se da região onde seria o dente 45 até a região onde estaria o dente 47, englobando de forma elíptica a área contendo a lesão hiperplásica e ulcerada. O tecido hiperplásico foi removido (Figura 2A) e, em seguida, os tecidos moles adjacentes foram descolados delicadamente, permitindo a exposição do leito com osteonecrose associada a bisfosfonatos. A área de sequestro ósseo foi removida por meio de curetagem e as adjacências da área com osteonecrose foram sauserizadas, por meio de instrumento rotatório com broca multilaminada a $30.000 \mathrm{rpm}$ e sob irrigação constante, até que as margens ósseas apresentassem sinal clínico de osso sadio (Figura 2B). Sobre o leito ósseo foram colocadas membranas confeccionadas com plasma rico em fibrina leucocitária L-PRF, obtidas a partir de amostra de sangue coletada da própria paciente previamente à cirurgia, em seis tubos de $10 \mathrm{ml}$ sem uso de anticoagulante (Figura 2C). As amostras foram centrifugadas imediatamente após a coleta, a $3.000 \mathrm{rpm}$ por 12 minutos, conforme protocolo de ChouKroun ${ }^{5}$. A sutura foi realizada sem tensão tecidual e em primeira intenção com pontos simples, usando fio monofilamentar de Nylon 5-0 (Figura 2D).

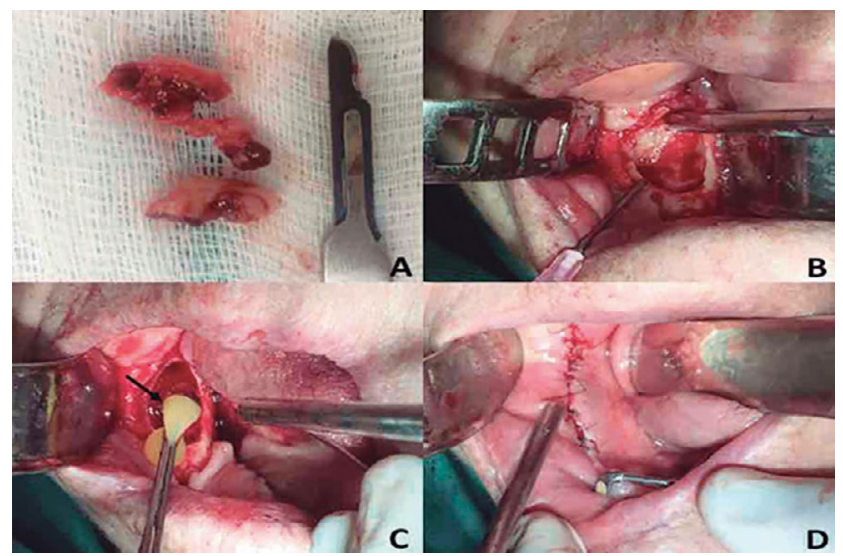

Figura 2 - Imagens transoperatórias da remoção cirúrgica da lesão hiperplásica e da área de sequestro ósseo tratada com preenchimento do defeito ósseo com L-PRF

Fonte: elaboração dos autores.

Nota: A) Lesão hiperplásica removida; B) Imagem da área de sequestro ósseo com dimensões aproximadas de $10 \mathrm{~mm} \times 15 \mathrm{~mm}$, após curetagem e sauserização com brocas; C) Imagem da colocação de membranas (indicada por seta) confeccionadas com plasma rico em fibrina leucocitária L-PRF; D) Imagem da sutura realizada sem tensão e em primeira intenção com pontos simples, usando fio monofilamentar de Nylon 5-0.
Os cuidados pós-operatórios envolveram afastamento de atividades físicas, crioterapia com compressas de gelo por 30 minutos a cada 2 horas nas primeiras 24 horas. $\mathrm{O}$ manejo medicamentoso foi desenvolvido em dois tempos: nas primeiras 48 horas, ainda durante a internação hospitalar, por meio de uso endovenoso, envolveu antibióticos, com Ampicilina associada a Sulbactam, com dose de $1.000 \mathrm{mg}$ a cada 6 horas, e analgésicos, com uso de Dipirona sódica, na dose de $1.000 \mathrm{mg}$ a cada 6 horas, e Cetoprofeno, na dose de $100 \mathrm{mg}$ a cada 12 horas. A partir das 48 horas pós-operatórias, após a alta hospitalar, iniciou-se o segundo momento medicamentoso, por meio de medicação via oral, com antibióticos, Amoxicilina $(875 \mathrm{mg}$ ) associada à Clavulanato de potássio (125 mg), a cada 12 horas, por 14 dias, e analgésicos, com uso de $10 \mathrm{mg}$ de Cetorolaco de trometamina, via sublingual, a cada 6 horas por 3 dias, e $4 \mathrm{mg}$ de Dexametasona, a cada 12 horas por 5 dias.

A paciente retornou quinze dias após a intervenção cirúrgica para remoção de sutura, sem sinais clínicos de inflamação e infecção e sem sintomatologia dolorosa, mas com deiscência parcial da sutura, com o tecido ósseo recoberto pela membrana de L-PRF. A orientação foi seguir com alimentação de consistência pastosa para evitar trauma no local, mantendo higienização adequada e bochechos com colutório à base de Digluconato de clorexidina $0,12 \%$, por 1 minuto a cada 12 horas. Quinze dias após a realização do procedimento, a paciente retornou com área de ferida cirúrgica apresentando recobrimento com tecido de granulação e sinais clínicos iniciais de cicatrização de mucosa em estágio compatível para o período pós-operatório, sendo mantidos os bochechos com colutório à base de clorexidina.

A avaliação pós-operatória de 60 dias decorridos do procedimento cirúrgico evidenciou presença de mucosa normal recobrindo a área operada, o que se manteve da mesma forma no controle clínico e tomográfico de 10 meses pós-operatório, conforme Figura 3 (A e B), em que se observa a manutenção do processo de cicatrização do tecido gengival e o reparo do tecido ósseo, o que caracteriza o sucesso da terapia empregada.

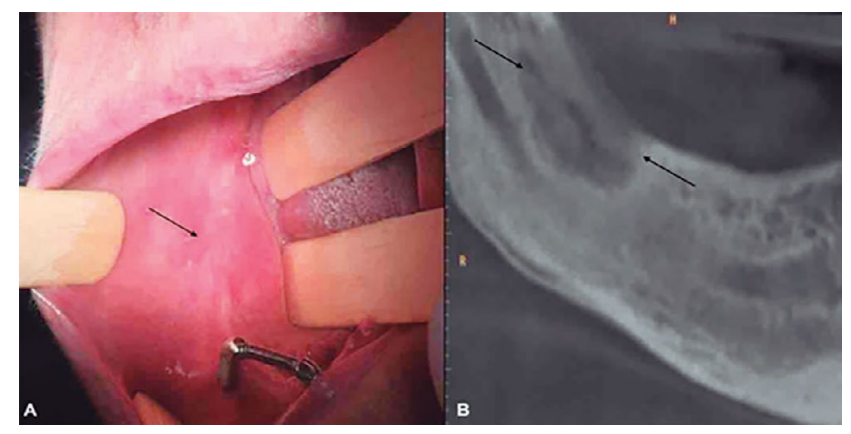

Figura 3 - A) Imagem clínica (indicada por seta) de 8 meses pós-operatório da área de osteonecrose mandibular tratada com membranas de plasma rico em fibrina leucocitária (PRF-L) - B) Imagem tomográfica (indicada por seta) de 8 meses pós-operatório da área de osteonecrose mandibular tratada com membranas de plasma rico em fibrina leucocitária (PRF-L)

Fonte: elaboração dos autores. 


\section{Discussão}

Os mecanismos de ação dos bisfosfonatos incluem diminuição da reabsorção óssea pela inibição da ação osteoclástica, indução de apoptose de osteoclastos, ação antiangiogênica e alteração da remodelação óssea fisiológica. Isso gera incapacidade de o tecido ósseo reparar microfraturas por estresse repetitivo, que, somado à diminuição da irrigação terminal mandibular, torna essa região mais propícia à ocorrência de osteonecrose associada à bisfosfonatos.

De acordo com Salvatore et al. ${ }^{6}$ (2006), o risco de osteonecrose mandibular em pacientes que utilizam compostos bisfosfonatos por via endovenosa é significativamente maior quando comparado a pacientes que fazem uso dessa medicação por via oral. No caso relatado, havia histórico do uso de Alendronato de sódio $10 \mathrm{mg}$, por via oral, a fim de prevenir a evolução de um quadro de osteopenia para osteoporose. A partir da instalação de uma prótese mucoimplantossuportada com movimentação ínfero-superior na região posterior, que causava trauma leve e crônico na região posterior de mandíbula, desenvolveu-se a osteonecrose mandibular.

A etiopatogenia da osteonecrose não está bem definida na literatura, mas as principais hipóteses para a ocorrência da osteonecrose mandibular associada à compostos bisfosfonatos incluem alteração do processo de remodelação óssea, supressão de reabsorção óssea, inibição da angiogênese, microtrauma, supressão de imunidade, deficiência de vitamina $\mathrm{D}$, toxicidade de tecidos moles por acúmulo de fármacos, inflamação e infecção ${ }^{7}$. Apesar da baixa taxa de complicações associadas ao seu uso, há inúmeros relatos do desenvolvimento de osteonecrose mandibular após extrações dentárias ${ }^{4}$. Isso pode ocorrer pelo fato de o metabolismo ósseo mandibular tornar-se lento em pacientes que fazem uso crônico de bisfosfonatos, o que poderia permitir que a contaminação bacteriana não fosse combatida rapidamente pela resposta imune do paciente, por isso, há maior propensão ao desenvolvimento de osteonecrose mandibular ${ }^{2}$.

A osteonecrose pode se manter assintomática por semanas, meses ou até mesmo anos, mas, quando sinais e sintomas clínicos aparecem, estão associados com dor, mobilidade dentária, edema, eritema e ulceração ${ }^{6}$. A paciente do presente estudo referia sintomatologia dolorosa na região onde estariam os dentes 46 e 47, infecção bucal recorrente e apresentava ainda hiperplasia ulcerativa associada à supuração na área afetada. Estudos epidemiológicos indicam uma incidência estimada de 0,1 caso para os 100.000 usuários de bisfosfonatos por ano ${ }^{2}$ . A partir do trabalho de Lin et $\mathrm{al}^{8}$. (2014), com pacientes portadores de osteoporose que faziam uso de Alendronato de sódio por via oral, observou-se que a incidência de osteonecrose de mandíbula associa- da ao uso de bisfosfonatos foi extremamente baixa e o risco de desenvolvimento dessas lesões não foi elevado nos primeiros quatro anos após o início do tratamento.

A American Association of Oral and Maxillofacial Surgeons (AAOMS) ${ }^{7}$ considera a prevenção como o tratamento chave para lidar com a osteonecrose mandibular. A consulta com o cirurgião-dentista antes de iniciar o tratamento reduz consideravelmente o risco de desenvolver osteonecrose mandibular no caso de intervenções que podem desencadear a osteonecrose, como a extração dentária.

A suspensão do uso de bisfosfonatos orais pode levar à melhora gradual e até à reparação espontânea da área de exposição óssea. De modo geral, o tratamento do paciente com diagnóstico estabelecido de osteonecrose mandibular, independentemente do estágio da doença, inclui controle da dor e da infecção de tecidos duros e moles, a fim de preservar a qualidade de vida do paciente. Sempre é recomendável abordagens conservadoras com reforço da higiene oral, verificações odontológicas periódicas, enxaguatórios orais com clorexidina e tratamento com antibiótico, sendo o manejo cirúrgico aconselhado apenas nos pacientes em estágios avançados da doença e naqueles em que o tratamento conservador não obteve sucesso ${ }^{1,6,9}$. Outra alternativa de tratamento que pode ajudar é o uso de concentrados plaquetários, que são produtos autólogos que contêm altas concentrações de fatores de crescimento por derivados de plaquetas que atuam como moléculas de adesão celular requeridas durante a migração celular, osteoindução, epitelização de feridas e osseointegração, sendo utilizados para estimular e acelerar o reparo dos tecidos ${ }^{5}$.

Assim, este trabalho teve o objetivo de descrever, por meio de relato de caso, o uso do plasma rico em fibrina leucocitária L-PRF como forma de favorecer a reparação óssea e a cicatrização dos tecidos moles em casos de osteonecrose associada ao uso de compostos bisfosfonatos.

Em relação aos achados clínicos, quatro estágios de osteonecrose mandibular associada a bisfosfonatos podem ser identificados, segundo diretrizes da AAOMS de 2014. O estágio 0 é aquele em que não há evidência clínica de osso necrótico. Os achados clínicos, radiográficos e sintomatologia são inespecíficos. No estágio 1, observam-se exposição e necrose óssea ou fístula, porém o paciente está assintomático e sem evidência de infecção. No estágio 2 , há exposição e necrose óssea ou fístulas associadas aos sinais e sintomas clínicos de infecção (dor e eritema, com ou sem secreção purulenta), que era o estágio em que o caso relatado se encontrava. No estágio 3 , há área de exposição e necrose óssea ou fístulas associadas à infecção em pacientes com dor, infecção e um ou mais dos seguintes aspectos: osso exposto e necrótico, que se estende para além da região do osso alveolar, ou seja, borda inferior e ramo na mandíbula, seio maxilar e zigoma na maxila, re- 
sultando em fratura patológica, fístula extraoral, comunicação oroantral ou oronasal ou osteólise, estendendo-se para a borda inferior da mandíbula ou fossa sinusal ${ }^{2-5,8}$. O caso relatado encontrava-se no estágio 2 no momento da reintervenção cirúrgica, apresentando fístula associada à necrose óssea, com sintomas e sinais clínicos de infecção.

A dificuldade em tratar osteonecrose mandibular destaca a importância da prevenção. A suspensão do uso de bisfosfonatos orais pode levar à melhora gradual e até à reparação espontânea da área de exposição óssea. Em geral, a literatura preconiza o tratamento odontológico desses pacientes de maneira atraumática, evitando extrações dentárias e outras cirurgias orais ou periodontais que expõem ou manipulam o osso, esses procedimentos devem ser feitos somente em casos de emergência, quando a dor dental ou infecção não pode ser resolvida de outra forma, principalmente em pacientes que estão utilizando bisfosfonatos intravenosos ${ }^{5,6}$. Pacientes que utilizam bisfosfonatos, por via oral, há mais de quatro anos, em caso de intervenção cirúrgica, devem interromper o uso da medicação no mínimo três meses antes e retornar somente três meses após a intervenção, caso seja possível do ponto de vista sistêmico ${ }^{8}$.

Para o dentista, a preocupação em relação aos compostos bisfosfonatos é que eles alteram a atividade osteoclástica e, por isso, geram alterações no metabolismo ósseo, o que é muito importante para procedimentos dentários cirúrgicos. Por isso, são importantes a avaliação e o tratamento dentário antes de começar a terapia com bisfosfonatos ${ }^{6,9}$.

As osteotomias segmentares, parciais ou totais, consideradas procedimentos cirúrgicos radicais, estão indicadas apenas em casos severos, quando o osso necrótico extenso estiver presente na mandíbula, aproximando-se ou envolvendo o osso basal, ou quando estiver presente uma fístula orocutânea. No entanto, seguem sendo tratamentos controversos, com alta morbidade e efeito negativo sobre a qualidade de vida dos paciente ${ }^{10}$. Por isso, no caso apresentado, optou-se pela realização de uma abordagem conservadora ao invés do tratamento radical por meio de ressecção segmentar parcial.

Recentemente, avanços nas áreas de biologia celular e molecular permitiram apresentar as funções dos fatores de crescimento e sua participação nas diferentes fases de cicatrização de feridas, podendo ser aplicado em casos de osteonecrose dos maxilares, especificamente o L-PRF, que resulta em uma aceleração na cura, reduzindo o risco de contaminação, edema e dor pós-operatória, sendo um método completamente inofensivo, uma vez que é preparado a partir do sangue do próprio paciente, eliminando a possibilidade de transmissão de doenças parenterais, bem como alergias ou reações imunes de rejeição. Isso ajuda na homeostase, evita a deiscência gengival e favorece a remodelação e a cicatrização dos tecidos moles e duros. De fato, a atividade biológica da molécula de fibrina é responsável pela capacidade cicatricial promovida pelo L-PRF 5 .

Assim, no caso relatado, seguiu-se o protocolo ChouKroun para confecção das membranas de concentrado plaquetário leucocitário ${ }^{5}$. Após o debridamento da área com osteonecrose, o defeito ósseo foi preenchido com as membranas e, dez meses após a realização da cirurgia, os resultados clínicos adequados, em termos cicatriciais, foram mantidos, uma vez que a osteonecrose mandibular associada a compostos bisfosfonatos não apresentou recidiva e o rebordo alveolar ficou coberto por mucosa sadia e sem exposição óssea ou sinais de infecção.

Uma compreensão detalhada sobre a frequência e as possíveis complicações do uso de bisfosfonatos é importante para que os profissionais da saúde aconselhem adequadamente seus pacientes sobre a relação de risco e benefício durante a realização dos procedimentos. Para tanto, os profissionais devem estar atentos à anamnese no que tange ao uso de bisfosfonatos pelos seus pacientes, especialmente quando necessitarem de procedimentos invasivos como cirurgias odontológicas.

\section{Considerações finais}

O uso de L-PRF é uma opção de tratamento para a osteonecrose mandibular em estágio 2 , pois estimula e acelera o reparo ósseo e a cicatrização dos tecidos moles, sendo um tratamento conservador e de baixa complexidade.

\section{Agradecimentos}

Aos cirurgiões-dentistas Dr. Gabriel Eduardo Fernandez e Dr. Fernando Indart Reis, pelo auxílio técnico na execução deste trabalho.

\section{Abstract}

Bisphosphonates are antiresorptive acting specifically on the activity of osteoclasts. A serious complication of their use is osteonecrosis of the jaw, defined as an area of exposed bone in the maxillofacial area without resolve spontaneously over a period of at least 8 weeks in patients with history of use of bisphosphonate compounds, but which have not been subjected to radiotherapy in the head and neck. Conservative treatments are recommended, but the literature results are controversial and not always effective. So new approaches such as the use of platelet concentrates, have been suggested. Swill autologous products containing high concentrations of growth factors that act as cell adhesion molecules, accelerating bone repair. Objective: describe, through case report the use of fibrin rich plasma and leukocyte (L-PRF) as treatment of jaw osteonecrosis. Case report: female patient, 79, diagnosed with jaw osteonecrosis associated with bisphosphonate use, treated by conventional surgery involving bone curettage and flap rotation, but without success. Surgical 
technique has undergone modification, involving the use of leukocyte rich plasma fibrin (L-PRF) in order to accelerate bone repair process and ensure the healing of soft tissue. Final considerations: the use of L-PRF as treatment of jaw osteonecrosis stimulates bone healing and speeds the healing of tissue moles It is alternative effective of treatment.

Keywords: Bisphosphonates. L-PRF. PRF. Osteonecrosis.

\section{Referências}

1. Abtahi J, Agholme F, Aspenberg P. Prevention of osteonecrosis of the jaw by mucoperiosteal coverage in a rat model. Int J Oral Maxillofac Surg 2013; 42:632-6.

2. Tardasta A, Sjöman R, Loes S, Abtahi J. Bisphosphonate associated osteomyelitis of the jaw in patients with bony exposure: prevention, a new way of thinking. J Appl Oral Sci 2015; 23(3):310-4.

3. Matthew R, David B. The pathogenesis of bisphosphonate - related osteonecrosis of the jaw: so many hypotheses, so few data. J Oral Maxillofac Surg 2009; 67(5 suppl.):61-70.

4. Leon A. Oral Bisphosphonates as a cause of bisphosphonate - related osteonecrosis of the jaws. Clinical findings, assessment of risks, and preventive strategies. J Oral Maxillofac Surg 2009; 67(5 suppl.):35-43.

5. Durán C, Peña F, García R, López J. The role of Leucocyte-rich and platelet-rich fibrin (L-PRF) in the treatment of the medication-related osteonecrosis ofthe jaws (MRONJ). J Clin Exp Dent 2017; 9(8):1051-9.

6. Salvatore L, Fantasia J, Carlson E. Bisphosphonate-related osteonecrosis of the jaw: background andguidelines for diagnosis, staging and management. Oral Maxillofacial Surgery 2006 ; 102(4)433-41.

7. Salvatore L, Thomas B, Fantasia J, Aghaloo T, O'Ryan F. American Association of Oral and Maxillofacial Surgeons Position Paper on Medication-Related Osteonecrosis of the Jaw - 2014 Update. J Oral Maxillofac Surg 2014; 72(10):1938-56.

8. Lin T, Yang C, Kao Y, Lin S. Incidence andrisk of osteonecrosis of the jaw among the Taiwan osteoporosis population. Osteoporos Int 2014; 25(5):1503-11.

9. Rodriguez F, Sánchez R. Treatment ofosteonecrosis of the jaw related to bisphosphonates and other antiresorptive agents. Med Oral Patol Oral Cir Bucal 2016; 21(5):595-600.

10. Carlson E, Jonh D. The role of surgical resection in the management of bisphosphonate-related osteonecrosis of the jaws. J Oral Maxillofac Surg 2009; 67(5 suppl.):85-95.

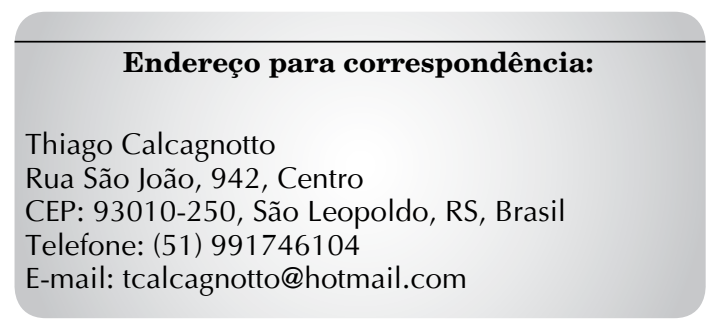

Recebido: 07/11/17. Aceito: 05/12/17. 